\title{
Oxidant stress: the role of nutrients in cell-lipoprotein interactions
}

\author{
Denis Blache*, Laurence Gesquière, Nadine Loreau and Phillipe Durand \\ INSERM U498, Biochimie des Lipoprotéines et Interactions Vasculaires, Université de Bourgogne, 21033-Dijon, France
}

\begin{abstract}
Oxidant stress is increasingly becoming an important hypothesis to explain the genesis of several pathologies, including cancer, atherosclerosis and also ageing. Beside a few rare genetic defects, dietary factors are thought to play a key role in the regulation of the production of reactive oxygenated species. An imbalance between nutrients, and in particular those involved in antioxidant status, could explain the onset of an enhanced production of free radicals. We will briefly review information concerning oxidation of lipids and lipoproteins which lead to atherothrombosis. We also present new findings supporting a role for blood platelets in generating oxidant species. New data are also described concerning the role of oxygenated derivatives of cholesterol, oxysterols, in cellular cholesterol efflux and NO production. Also, new developments relating to the influence of direct effects of free radicals on cellular cholesterol homeostasis are presented. Finally, the in vitro effects of butyrate, a natural short-chain fatty acid produced by bacterial fermentation, in the protection against free radical-mediated cytotoxicity are discussed. These data provide information on the mechanisms of dietary antioxidants in preventing oxidant stress.
\end{abstract}

\section{Résumé}

\begin{abstract}
Au côté des rares cas d'origine génétique, les facteurs nutritionnels (déséquilibres alimentaires, déficience en nutriments antioxydants) jouent des rôles cruciaux dans la modulation de la production d'espèces actives de l'oxygène, conduisant à l'établissement d'un stress oxydant, situation métabolique de plus en plus reconnue comme susceptible d'être à l'origine de nombreuses pathologies comme les cancers, l'athérosclérose et également le vieillissement. Après avoir brièvement rappelé les données concernant l'oxydation des lipides et des lipoprotéines susceptibles de conduire au développement de l'athéro-thrombogenèse, nous présentons des données récentes et originales indiquant que les plaquettes sont en fait capables à l'instar d'autres cellules, de produire des formes actives de l'oxygène susceptibles de modifier les LDL. Des résultats originaux sont également exposés concernant l'effets des oxystérols, produits d'oxydation du cholestérol générés au cours de l'oxydation des LDL ou présents dans l'alimentation, sur deux paramètres importants comme l'efflux du cholestérol cellulaire et la production de monoxyde d'azote. De plus, des données nouvelles relatives à l'effets du stress oxydant et son inhibition par des antioxydants d'origine nutritionnelle sont exposées sur l'homéostasie du cholestérol cellulaire. Enfin, dans ce contexte, les effets potentiellement antiathérogènes d'un acide gras à courte chaîne produit par la fermentation bactérienne, le butyrate, sont décrits sur la protection de cellules en culture vis-à-vis d'un stress oxydant in vitro. Ces éléments contribuent à apporter de nouvelles informations renforçant la notion de fonctionnalité des nutriments dans la protection du stress oxydant en relation avec la pathogenèse.
\end{abstract}

Oxidative stress: Lipoproteins: Platelets: Vascular smooth muscle: Butyrate

Although free radicals have been known about for a long time in chemistry, it is only recently that they have been of interest to scientists involved in pathology and/or nutrition. Oxidative stress, which often arises as a result of an imbalance in antioxidant status, has been implicated in ageing and a large number of important human diseases

Abbreviations: OS, oxysterols; TBARS, thiobarbituric acid-reactive substances.

*Corresponding author: Dr Denis Blache, fax +33 3803933 00, email dblache@u-bourgogne.fr 
such as atherosclerosis and cancer (Halliwell \& Cross, 1994). As the oxidant hypothesis becomes increasingly documented, in particular the biological consequences of changes in LDL metabolism, the present paper focuses on atherothrombogenesis. In the present paper, rather than listing the involvement of nutrients which protect against free radical production, we shall consider new possibilities that may result in enhancement or inhibition of atherothrombogenesis through cell-lipoprotein interactions. In particular, we will describe recent information on the role of blood platelets as pro-oxidant agents, new results on the role of some oxidation products such as oxysterols (OS), and finally recent findings on the putative beneficial effects of butyrate.

\section{Platelet-mediated LDL modifications}

Several lines of evidence support the notion that oxidative modification of LDL is a key factor in the development of cardiovascular diseases. LDL can be oxidized by metals or by incubation with cells such as endothelial cells or macrophages; once oxidized, LDL are no longer recognized by their classical apolipoprotein $\mathrm{B} / \mathrm{E}$ receptor but by scavenger receptors present on macrophages. These receptors are not down-regulated, and macrophages accumulate large amounts of oxidized lipids and transform into foam cells recovered in vascular wall, leading to the development of the atheroma plaque.

The most compelling evidence in favour of this hypothesis has been that the treatment of experimental animals with a variety of antioxidants results in an inhibition of the development and progression of atherosclerosis (Steinberg et al. 1989). Human studies also indicate further contributing factors; for instance, the susceptibility of LDL to $\mathrm{Cu}$-mediated oxidation in vitro was correlated with the severity of angiographically-determined coronary atherosclerosis (Regnström et al. 1992). Also plasma titres of autoantibodies against oxidized LDL were significantly related to the progression of atherosclerosis in Finns (Salonen et al. 1992).

We found that platelets were able to generateoxidant species and consequently to oxidize LDL, leading to a form promoting atherosclerosis (Blache et al. 1995a). We used dichlorofluorescein diacetate which was in the reduced non-fluorescent form that was able to penetrate human platelets. Non-specific intracellular esterases liberated the esters. The reduced form of dichlorofluorescein then reacts with oxidizing enzymes or oxidant species and becomes fluorescent as dichlorofluorescein. Fig. 1 shows that dichlorofluorescein fluorescence increased only when platelets were stimulated by comparison with resting platelets. This result indicates that on stimulation platelets produced important oxidant species. The levels of these oxygenated species were increased in the presence of catalase (EC 1.11.1.6) and GSH peroxidase (EC 1.11.1.9) inhibitors (aminotriazol and $N$-ethyl maleimide respectively). These findings indicate that $\mathrm{H}_{2} \mathrm{O}_{2}$ or peroxides were produced during activation. The production of oxidant species was opposed by an inhibitor of lipoxygenases such as nordihydroguaiaretic acid. These results were confirmed by the measurement of indices of oxidation such as thiobarbituric acid-reactive substances (TBARS) and dienes. These variables were increased with LDL and significantly elevated when platelets were stimulated with a calcium ionophore. LDL incubations with aminotriazol and $N$-ethyl maleimide enhanced TBARS measured with stimulated platelets. Furthermore, compared with the appropriate controls, platelet-modified LDL stimulated the biosynthesis of the pro-atherogenic cholesteryl esters when incubated with macrophages (Fig. 2). Although to a lesser extent than acetyl- or oxidized-LDL, cholesteryl ester biosynthesis occurred significantly $(P<0.001)$ more than with native LDL. It is also interesting to note that when platelets were first pre-incubated in vitro with $\alpha$-tocopherol, their propensity to oxidize LDL was reduced.

Although in the future animal or human studies should be performed in vivo, these findings suggest that deficiency of

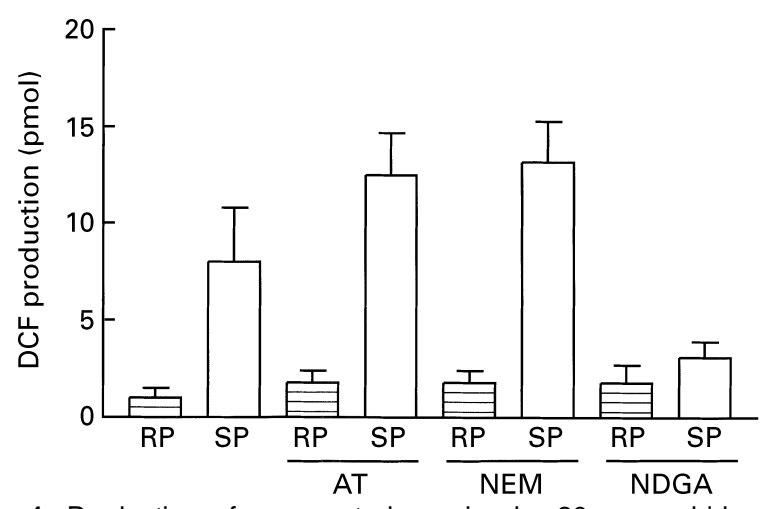

Fig. 1. Production of oxygenated species by $20 \mu \mathrm{M}$-arachidonatestimulated blood platelets (SP). Human platelets were loaded with the reduced form of the fluorescent probe dichlorofluorescein (DCF). This compound becomes fluorescent in the presence of oxygenated species and oxidases. The fluorescence was significantly increased $(P<0.001)$ in SP compared with resting platelets (RP). This fluorescence was enhanced after preincubation with catalase (EC 1.11.1.6) inhibitor aminotriazol (AT), and with GSH peroxidase (EC 1.11.1.9) inhibitor $N$-ethyl maleimide (NEM). An inhibition was found with an inhibitor of lipoxygenase, nordihydroguaiaretic acid (NDGA). These experiments indicated that hydroperoxides were produced during platelet activation. Values are means and standard deviations represented by vertical bars.

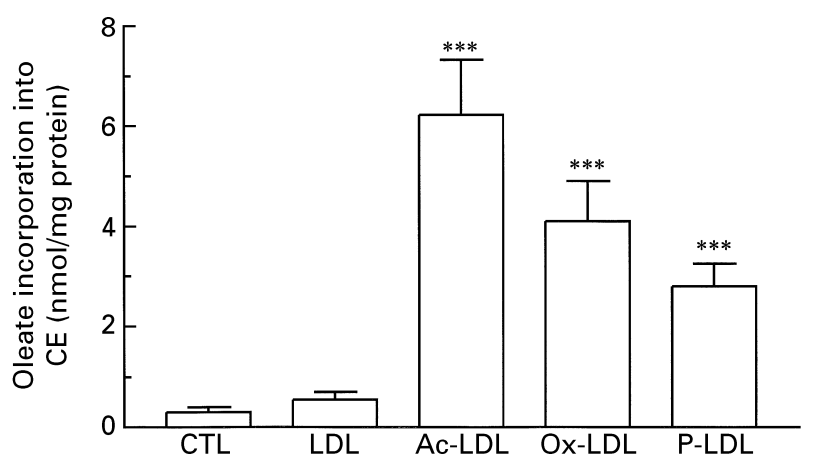

Fig. 2. Effects of platelet-modified LDL (P-LDL) on cholesteryl ester (CE) biosynthesis. After incubations with stimulated platelets, LDL were re-isolated and incubated $(50 \mu \mathrm{g} / \mathrm{ml})$ for $14 \mathrm{~h}$ with cultured macrophages (P388D1). The biosynthesis of CE, measured as $\left[{ }^{14} \mathrm{C}\right]$ oleate incorporation, was compared with that with acetyl-LDL (Ac-LDL) and copper-oxidized LDL (Ox-LDL). Values are means and standard deviations represented by vertical bars. Mean values were significantly different from those with native LDL: ${ }^{* \star *} P<0.001$. CTL, control. 
antioxidant nutrients such as vitamin E may result in an imbalance, leading to increased platelet-induced LDL oxidation.

\section{Oxysterols as products of LDL oxidation}

Among the oxidation products of lipoproteins such as fatty acid peroxides and aldehydes, oxidized products of cholesterol (OS; Fig. 3) are produced. In the course of oxidation of LDL, cholesteryl hydroperoxides are formed (Malavasi et al. 1992) and they can enhance the susceptibility of LDL to metal-mediated oxidation (Blache et al. $1995 \mathrm{~b}$ ). In this process, large amounts of 7-oxidized derivatives were found (Blache et al. 1998). OS may also be absorbed from food, as they were identified in some processed foods, e.g. egg-containing products and powdered milk (Paniangvait et al. 1995). In addition to their demonstrated atherogenicity (Peng et al. 1991), OS have also shown other detrimental properties. OS exhibit cytotoxicity (Sevanian et al. 1995), inhibit hydroxymethylglutaryl-CoA reductase (EC 1.1.1.34; Kandutsch et al. 1978 ) and cause an increase in cholesteryl esters by stimulation of acyl-CoA:cholesterol acyltransferase activity (EC 2.3.1.26; Zhang et al. 1990). Involvement of these compounds in thrombosis has also been proposed, as a potentiation of platelet activity has also been reported after in vitro incubations with micromolar concentrations of OS (Blache \& Bontoux, 1988; Selley et al. 1996).

\section{Oxysterols and nitric oxide}

NO is known to be responsible for the vascular and endothelial-derived relaxing factor, and is synthesized from an arginine precursor by constitutive and inducible forms of NO synthase (EC 1.14.13.39) (Moncada \& Higgs, 1991). In addition to the vascular production (endothelium and smooth muscle cells) NO occurs in multiple sites such as macrophages, platelets and nervous tissues. It is thought that $\mathrm{NO}$ is one of the key mechanisms for the regulation of vascular tone, and hence of blood pressure. It has been reported that oxidized LDL decreases the production of NO in various cells (Yang et al. 1994, 1996). We have recently

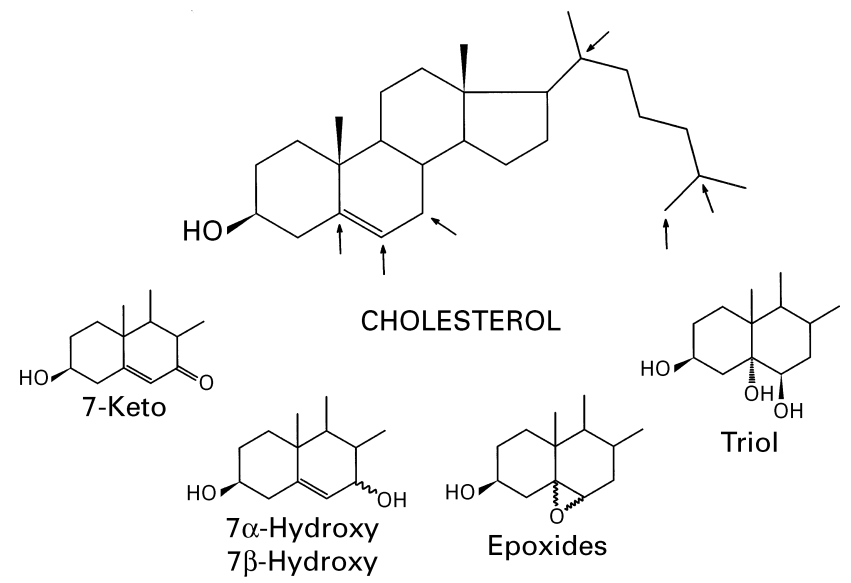

Fig. 3. Chemical structure of oxysterols. $\rightarrow$, Commonly encountered insertion of oxygenated groups (hydroxyl, ketone) either on the cholesterol ring or on the side chain. demonstrated, using lipopolysaccharide-stimulated rat peritoneal macrophages, that OS were key components of oxidized LDL responsible for the inhibition of NO production (Blache \& Durand, 1995). In fact, when OS were incorporated into native LDL, the oxidized LDL-mediated inhibition of NO production was fully reproduced. We have shown also that OS can impair the expression of the inducible form of NO synthase. From these findings we can propose that through an inhibition of the NO release OS may influence atherothrombogenesis by decreasing vascular relaxation and by enhancing platelet activity.

\section{Oxysterols and cholesterol efflux}

It has been demonstrated that when OS were incorporated into macrophages, they tended to reduce, as did oxidized LDL, the cellular efflux of cholesterol (Gelissen et al. 1996). It is necessary to realize that this process occurs mainly through a cholesterol reverse transport in which efflux is mediated by HDL (Rothblat et al. 1992). This property of these lipoproteins is one of their antiatherogenic activities described in epidemiological studies (Williams et al. 1979). We have recently demonstrated that when OS (e.g. 7-ketocholesterol) were incorporated into HDL, they greatly reduced the capacity of HDL to remove cholesterol from macrophages in the same way as that observed for oxidized HDL (Gesquière et al. 1997).

By decreasing the OS formed as a result of lipoprotein oxidative modifications, antioxidants may contribute to the regulation of cellular cholesterol homeostasis. Antioxidants added as preservatives in food may also decrease the amounts of OS ingested, and hence decrease their noxious atherothrombotic effects.

\section{Direct effects of oxidant stress on cellular cholesterol homeostasis}

Until now, effects of free radicals have mainly been studied in LDL, and apart from toxicity, information concerning the direct action of free radicals on cells is scarce. Recent work carried out with rabbit vascular smooth muscle cells has shown that oxidant stress induced by phorbol esters resulted in an induction of the scavenger receptor (Gong \& Pitas, 1995; Mietus-Snyder et al. 1997). We have studied the direct effects of free radicals on cellular cholesterol metabolism. For this purpose a free radical generator (azobisamidinopropane dihydrochloride) was used, and weak oxidative stress conditions were set up in cultured aortic smooth muscle cells $\left(\mathrm{A}_{7} \mathrm{R}_{5}\right)$ so that cell viability was not significantly altered. After free radical action the cells presented a significant accumulation of cholesterol (Gesquière et al. 1998), which may contribute to their transformation into lipid-laden foam cells. This transformation appears to be due to: (1) an increase in cholesterol biosynthesis and esterification (by activation of hydroxymethylglutaryl-CoA reductase and acyl-CoA: cholesterol acyltransferase respectively); (2) a decrease in the hydrolysis of cell cholesteryl esters (by inactivation of neutral cholesteryl ester hydrolase); (3) a decrease in HDLmediated cholesterol efflux. In most of our experiments these effects were opposed by incubation in the presence of 
antioxidants such as $\alpha$-tocopherol or $N$-acetylcysteine. Our results (Gesquière et al. 1999) suggest that free radicals which may result from a nutrient imbalance might be atherogenic, not only through modifications of lipoproteins, but also through action on cellular cholesterol metabolism. Experiments carried out with antioxidants suggested that they could normalize this oxidative stress-induced process.

\section{Butyrate: an anti-atherogenic agent?}

Butyrate is a natural short-chain fatty acid present in dairy products and produced in the mammalian colon by bacterial fermentation (Bugaut \& Bentéjac, 1993). The occurrence of this fatty acid is enhanced by polysaccharide ingestion, and it might explain the benefits of dietary fibre intake described in several epidemiological studies (Spiller, 1994). Butyrate has been reported to act as a potent anti-proliferative agent, to be a cell differentiation promoter and to alter gene expression (Feng et al. 1996). These properties, along with the findings that butyrate could modulate the response to receptors for growth factor, have led to the proposal that butyrate might be effective against colon cancer (Velázquez \& Rombeau, 1997).

Recently, studies have been designed to examine whether butyrate can provide protection against free radicals in vitro. We found that when macrophages were incubated in the presence of millimolar concentrations of butyrate they appeared to be less sensitive to free radical-induced oxidative stress produced by using azobisamidinopropane dihydrochloride (Fig. 4). These effects were associated with a decrease in one of the indices of lipoperoxidation (TBARS). Moreover, when LDL were incubated in the presence of butyrate-pre-incubated macrophages their propensity to modify LDL was significantly reduced, as assessed by electrophoretic mobility. These findings indicate that butyrate may act as an 'antioxidant' nutrient by conferring protection against free radicals in macrophages incubated with butyrate, and may diminish the production

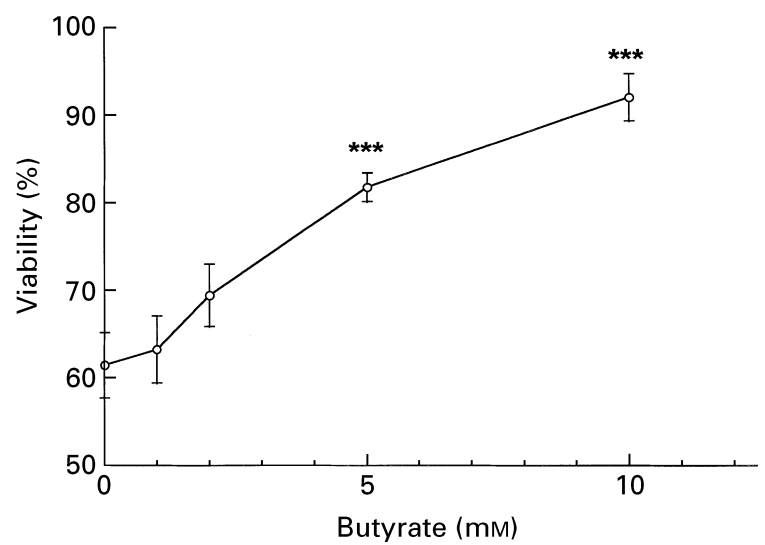

Fig. 4. Effects of different concentrations of butyrate on cell viability. Butyrate-incubated macrophages (P388D1) were treated with a free radical generator (azobisamidinopropane dihydrochloride) to obtain about $60 \%$ viability. Cell viability was assessed using the trypan blue staining. Values are means and standard deviations represented by vertical bars. Mean values were significantly different from those without butyrate: ${ }^{* * *} P<0.001$. of pro-atherogenic oxidized LDL. Although the precise mechanisms require further specific studies, which are underway in our laboratory, these findings are sufficiently interesting to address the question of whether butyrate could act as an anti-atherogenic agent. Based on this hypothesis, it is interesting to consider various attempts to stimulate the production of butyrate, e.g. by ingestion of high levels of dietary fibres.

\section{Concluding remarks}

The notion that oxidative stress may contribute to the pathogenesis of various diseases, including atherothrombosis and cancer, is supported by a large body of evidence. Although the precise mechanisms are not fully understood, they involve interactions between nutrients and cells. In cardiovascular pathology cell-lipoprotein interactions play a significant role, which is amplified when LDL are oxidized and act as carriers for oxidized agents. The role of dietary antioxidants is not yet conclusive, although the available evidence probably helps to substantiate this hypothesis. We have recently reported in elderly subjects that low-dose supplementation with vitamins and minerals can normalize the biological nutrient status in terms of improvement in antioxidant defence (Girodon et al. 1997). Some nutrients require further specific investigation, and are the subject of current research in our laboratory and around the world; for example, dietary or wine polyphenols such as flavonoids (Hertog et al. 1997) and resveratrol (Jang et al. 1997; Bessis et al. 1998), and also phytosterols (Ling \& Jones, 1995). However, it appears that a well-balanced low-fat diet with fruits, vegetables, fibres and a glass of wine is a reasonable choice to achieve optimal levels of circulating antioxidant nutrients, and should afford significant protection against morbidity and premature mortality.

\section{Acknowledgements}

The authors' work was supported by the Institut National de la Santé et de la Recherche Médicale (INSERM), the Conseil Régional de Bourgogne and the Université de Bourgogne. The support of ARCOL was also greatly appreciated. L. G. is supported by a fellowship from the Ministère de l'Education Nationale, de l'Enseignement Supérieure et de la Recherche.

\section{References}

Bessis R, Jeandet P, Adrian M, Breuil AC, Blache D, Meunier P \& Pirio N (1998) Un polyphénol remarqué: le resvératrol; pourquoi (A remarked polyphenol: resveratrol; why)? In Guide Vin et Santé (Guide Wine and Health), pp. 61-73 [S Azria, editor]. Montpellier, France: Les Editions du Voyage.

Blache D \& Bontoux G (1988) Biological effects of oxysterols on platelet function. Thrombosis Research 50, 221-230.

Blache D \& Durand P (1995) Oxysterols decrease the production of nitric oxide by macrophages. Comptes Rendus de la Société de Biologie 189, 1226.

Blache D, Durand P, Girodon F, Gesquière L \& Loreau N (1998) Determination of sterols, oxysterols and fatty acids of phospholipids in cells and lipoproteins: a one sample method. Journal of the American Oil Chemists' Society 75, 107-113. 
Blache D, Rodriguez C \& Davignon J (1995a) Platelet-induced oxidative low density lipoprotein modification. Atherosclerosis 115, S14.

Blache D, Rodriguez C \& Davignon J (1995b) Pro-oxidant effects of 7-hydroperoxycholest-5-en-3 $\beta$-ol on the copperinitiated oxidation of low density lipoprotein. FEBS Letters 357, 135-139.

Bugaut M \& Bentéjac M (1993) Biological effects of short-chain fatty acids in nonruminant mammals. Annual Review of Nutrition 13, 217-241.

Feng P, Ge L, Akyhani N \& Liau G (1996) Sodium butyrate is a potent modulator of smooth muscle cell proliferation and gene expression. Cell Proliferation 29, 231-241.

Gelissen IC, Brown AJ, Mander EL, Kritharides L, Dean RT \& Jessup W (1996) Sterol efflux is impaired from macrophage foam cells selectively enriched with 7-ketocholesterol. Journal of Biological Chemistry 271, 17852-17860.

Gesquière L, Loreau N \& Blache D (1997) Impaired cellular cholesterol efflux by oxysterol-enriched high density lipoproteins. Free Radical Biology and Medicine 23, 541-547.

Gesquière L, Loreau N, Minnich A, Davignon J \& Blache D (1999) Oxidative stress leads to cholesterol accumulation in vascular smooth muscle cells. Free Radical Biology and Medicine (In the Press).

Gesquière L, Loreau N \& Blache D (1998) Direct effects of free radicals on cholesterol homeostasis of vascular smooth muscle cells. Comptes Rendus de la Société de Biologie 193, 581.

Girodon F, Blache D, Monget AL, Lombart M, Brunet-Lecompte P, Arnaud J, Richard MJ \& Galan P (1997) Effect of two year supplementation with low dose antioxidant vitamins and/or minerals in elderly subjects on levels of nutrients and on antioxidant defense parameters. Journal of the American College of Nutrition 16, 357-365.

Gong QQ \& Pitas RE (1995) Synergistic effects of growth factors on the regulation of smooth muscle cell scavenger receptor activity. Journal of Biological Chemistry 270, 21672-21678.

Halliwell B \& Cross CE (1994) Oxygen-derived species: Their relation to human disease and environmental stress. Environmental Health Perspectives 102, Suppl. 10, 5-12.

Hertog MGL, Feskens EJM \& Kromhout D (1997) Antioxidant flavonols and coronary heart disease risk. Lancet 349, 699.

Jang MS, Cai EN, Udeani GO, Slowing KV, Thomas CF, Beecher CWW, Fong HHS, Farnsworth NR, Kinghorn AD, Mehta RG, Moon RC \& Pezzuto JM (1997) Cancer chemopreventive activity of resveratrol, a natural product derived from grapes. Science 275, 218-220.

Kandutsch AA, Chen HW \& Heiniger H (1978) Biological activity of some oxygenated sterols. Science 201, 498-501.

Ling WH \& Jones PJH (1995) Dietary phytosterols: A review of metabolism, benefits and side effects. Life Sciences 57, 195-206.

Malavasi B, Rasetti MF, Roma P, Fogliatto R, Allevi P, Catapano AL \& Galli G (1992) Evidence for the presence of

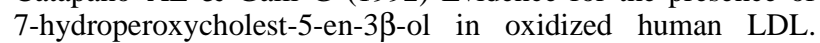
Chemistry and Physics of Lipids 62, 209-214.
Mietus-Snyder M, Friera A, Glass CK \& Pitas RE (1997) Regulation of scavenger receptor expression in smooth muscle cells by protein kinase $\mathrm{C}-\mathrm{A}$ role for oxidative stress. Arteriosclerosis, Thrombosis and Vascular Biology 17, 969-978.

Moncada S \& Higgs EA (1991) Endogenous nitric oxide: physiology, pathology and clinical relevance. European Journal of Clinical Investigation 21, 361-374.

Paniangvait P, King AJ, Jones AD \& German BG (1995) Cholesterol oxides in foods of animal origin. Journal of Food Science 60, 1159-1174.

Peng S-K, Hu B \& Morin RJ (1991) Angiotoxicity and atherogenicity of cholesterol oxides. Journal of Clinical Analysis 5, 144-152.

Regnström J, Nilsson J, Tornvall P, Landou C \& Hamsten A (1992) Susceptibility to low-density lipoprotein oxidation and coronary atherosclerosis in man. Lancet 339, 1183-1186.

Rothblat GH, Mahlberg FH, Johnson WJ \& Phillips MC (1992) Apolipoproteins, membrane cholesterol domains, and the regulation of cholesterol efflux. Journal of Lipid Research 33, 1091-1097.

Salonen JT, Ylä-Herttuala S, Yamamoto R, Butler S, Korpela H, Salonen R, Nyyssönen K, Palinski W \& Witztum JL (1992) Autoantibody against oxidised LDL and progression of carotid atherosclerosis. Lancet 339, 883-887.

Selley ML, McGuiness JA \& Ardlie NG (1996) The effect of cholesterol oxidation products on human platelet aggregation. Thrombosis Research 83, 449-461.

Sevanian A, Hodis HN, Hwang J, McLeod LL \& Peterson H (1995) Characterization of endothelial cell injury by cholesterol oxidation products found in oxidized LDL. Journal of Lipid Research 36, 1971-1986.

Spiller RC (1994) Pharmacology of dietary fibre. Pharmacology and Therapeutics 62, 407-427.

Steinberg D, Parthasarathy S, Carew TE, Khoo JC \& Witztum JL (1989) Beyond cholesterol. Modifications of low-density lipoprotein that increase its atherogenicity. New England Journal of Medicine 320, 915-924.

Velázquez OC \& Rombeau JL (1997) Butyrate: Potential role in colon cancer prevention and treatment. Advances in Experimental Medicine and Biology 427, 169-181.

Williams P, Robinson D \& Bailey A (1979) High density lipoprotein and coronary risk factors in normal man. Lancet $\mathbf{i}$, $72-75$.

Yang X, Cai B, Sciacca RR \& Cannon PJ (1994) Inhibition of inducible nitric oxide synthase in macrophages by oxidized lowdensity lipoproteins. Circulation Research 74, 318-328.

Yang XC, Galeano NF, Szabolcs M, Sciacca RR \& Cannon PJ (1996) Oxidized low density lipoproteins alter macrophage lipid uptake apoptosis, viability and nitric oxide synthesis. Journal of Nutrition 126, 1072S-1075S.

Zhang H, Basra HJK \& Steinbrecher UP (1990) Effects of oxidatively modified LDL on cholesterol esterification in cultured macrophages. Journal of Lipid Research 31, 1361-1369. 
